\title{
High-Risk, Non-Muscle Invasive Bladder Urothelial Carcinoma
}

National Cancer Institute

\section{Source}

National Cancer Institute. High-Risk, Non-Muscle Invasive Bladder Urothelial Carcinoma. NCI Thesaurus. Code C157511.

A high-grade bladder transitional cell carcinoma that does not invade muscle. It includes high-grade papillary stage Ta or T1 tumors and any patient with carcinoma in situ. 